\title{
Knowledge Management to Support Learning Analytics in Higher Education
}

\author{
Abdullah Alenezi \\ School of Aerospace, Transport and \\ Manufacturing \\ Cranfield University \\ Cranfield, UK \\ ab.alenezi@cranfield.ac.uk
}

\author{
Christos Emmanouilidis \\ School of Aerospace.Transport and \\ Manufacturing \\ Cranfield University \\ Cranfield, UK \\ Christosem@cranfield.ac.uk
}

\author{
Ahmed Al-Ashaab \\ School of Aerospace.Transport and \\ Manufacturing \\ Cranfield University \\ Cranfield, UK \\ a.al-ashaab@cranfield.ac.uk
}

\begin{abstract}
This paper argues based on evidence from the literature that learning analytics, when undertaken by higher education institutions, is not considered within a holistic knowledge management strategy, which could provide significant improvement to the outcomes of learning analytics. Particularly, a synthesis of knowledge extraction via learning analytics and appropriate handling of such knowledge via knowledge management is not typically implemented in higher education practices, but it constitutes a promising path to improving it, and eventually contributes to improving learning services. Essentially, knowledge management can support improvements and innovation in analytics tools, translate an organisation's strategic vision into action, and enable sharing of information among different actors. These are all necessary requirements for effective learning analytics.
\end{abstract}

Keywords-learning analytics, knowledge management, learning services.

\section{INTRODUCTION}

The increased uses of Virtual Learning Environments (VLEs) and Personalised Learning Environments (PLEs), as well as the ubiquitous availability of Massive Open On-Line Courses (MOOCs), are redefining the way learning organisations handle teaching, learning and assessment. Data generated from the interactions of teachers and learners with such environments constitute a rich source of information for assessing the effectiveness and indeed driving improvements to various learning services. Essentially, learning services are the support and enabling services that should be provided to key stakeholders (i.e. academic staff, admins and students) who are involved in an education programme by the Higher Education (HE) institution. These services aim to facilitate the learning process, and include the management and provision of teaching content, classrooms, libraries, research facilities and so on. The improvements can go beyond these services to include aspects such as student retention, student rates, institution competitive advantage, student attraction, online and in-class learning, digital library content, physical library content, learning material, support/extra courses, student-teacher ratios, the number of students in a classroom, facilities provided to students and many others. The knowledge obtained by the analysis of these data will serve as an input into improving the learning services and associated outcomes by directing the right improvements to the right places.
This paper provides evidence from a literature survey based on evidence from the literature that Learning Analytic (LA) has great potential for improving learning in HE institutions. This potential is realised and maintained when LA is considered within a holistic Knowledge Management (KM) strategy by these institutions. Particularly, KM could provide significant improvement to the outcomes of LA.

The paper is organised as follows: We start with a literature review that introduces the main discussion concepts: learning analytics, knowledge management, and learning services, and provides suggestions on how these concepts interact in the HE context. We provide some of the main issues facing LA and preventing its utilisation in higher education and we propose how KM may help improve LA if considered by higher education institution. We then provide a discussion on how proposed LA framework by some existing studies, although aim to address LA in a systematic and holistic manner within the overall organisational strategy, miss that knowledge management is needed to help an organisation translate its strategic vision into action. Finally, we provide a conclusion summarising the results and highlighting future work.

\section{LITERATURE REVIEW}

The literature review surveys LA used and/or proposed in $\mathrm{HE}$ and the role of KM. It highlights the importance of KM to support LA practices in $\mathrm{HE}$ and looks into aspects, if any, whereby LA and KM are combined in HE practices.

The review consults journal databases, library catalogues, topic-specific professional websites, and other relevant resources. Specific and technical search terms were used to search for the sources. Articles selected were recent and directly related to the topic, and were based on quantitative and/or qualitative studies. The review aims to provide an understanding of the relevance of the research and to place KM and LA in the context of higher education, and highlights how their integration can help improve learning services.

\section{A. Learning Analytics}

Learning analytics is essentially the use of evidence and data from learning environments to improve learning. LA can be defined as "the measurement, collection, analysis, and reporting of data about learners and their contexts, for purposes of understanding and optimising learning and the 
environments in which it occurs" [1]. LA also refers to the measurement, collection, analysis and reporting of data on the learners' progress as well as the learning context [2]. Consequently, these data are used to optimise and improve learning [3]. This view of LA is depicted in Fig. 1.

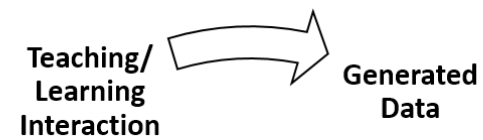

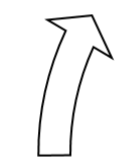

Improved Learning

\section{Learning Analytics}

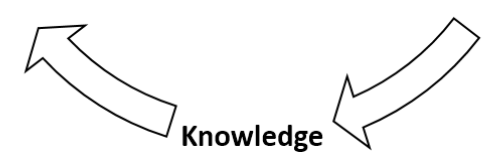

Fig. 1. LA uses learning data to improve learning

Fig. 1 shows that LA processes start with the generation of data from the learning/teaching interaction among the different players. The data collected then undergo the analysis stage. At this stage, different analysis methods can be used to understand the data and produce relevant results. The analyses conducted include statistical analysis, mathematical modelling and visualisation, among many others. LA platforms can be equipped with algorithms to perform various functions typically descriptive, predictive and prescriptive analytics. Descriptive analytics mainly describes or summarises large amounts of data. Predictive analytics provides institutions with information about the trend of certain behaviour. Prescriptive analytics allow institutions to undertake actionable measures for events probable to happen. Prescriptive analytics provides automation of actions in a feedback loop that could modify, optimise or pre-empt results [4]. When the analysis stage is complete, the results are produced. This is referred to as knowledge in the diagram. This knowledge is utilised back to improve the learning/teaching process.

Although the above view to LA is factual in the meaning that LA eventually boils down to improving learning, which is what is expected to do since learning institutions carry this aim as an ultimate goal, improved learning is one of several other benefits LA may bring about. For instance, learning analytics aims to provide helpful information to optimise the learning designs, outcomes and environment based on the analysis results [5]. Also, feeding back results to learners is necessary for make effective interventions [6].

These benefits can be viewed from a managerial point of view. For example, LA can help improve student management in terms of the courses offered and their content, the admission process, wellbeing of the students, etc. LA can help improve research management by providing insights into research focus, impact and necessary research facilities. Also, LA can offer improvement to the overall organisational management in terms of, for instance, directing recruitment, financing and investment.

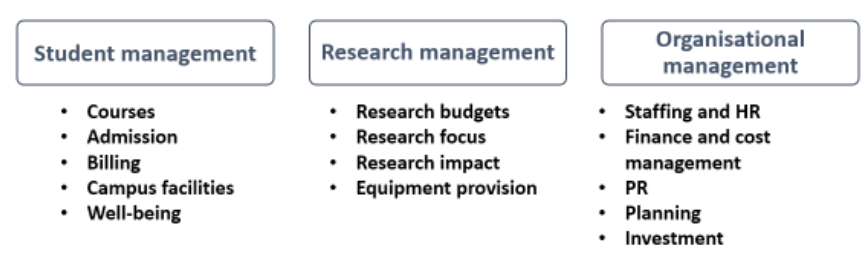

Fig. 2. LA can be considered from a managerial point of view in various aspects of an institution

Fig. 2 provides examples the three main areas of contribution of LA to HE from a managerial perception.

In addition to the above, the emergence of platforms that offer online learning for a large number of students has changed how learning analytics is used and deployed. Online learning solutions such as VLEs and MOOCs generate vast amounts of data as well as opportunities for learning analytics to utilise in order to optimise learning environments. In this particular context of VLEs and MOOCs, LA transforms from a welcome addition to a learning institution into a necessary means for the survival of the institution because with thousands of students, "technological" management offered by LA becomes inevitable [7].

Nevertheless, there are still many challenges for more efficient exploitation of learning analytics. These include building stronger connections between learning analytics and learning sciences, developing methods for working with a wide range of datasets for improving learning environments and focusing on the perspectives of learners and ethics [8]. Other challenges include the different perspectives of stakeholders regarding the vision and the methods to use to achieve the set goals [9]. Examples of such challenges are detailed in the following section.

\section{B. Knowledge Management in Higher Education}

Knowledge Management (KM) is the management of knowledge and information of an organisation in a systematic manner. It involves the process of obtaining, sharing and leveraging knowledge. Although there is no single widely accepted definition of KM, most of existing definitions share common notions to that definition

Knowledge management has gained credibility over the years not only by virtue of considerable research, but also through utilising it as a management tool in business organisations [10]. In fact, the business aspect of KM has overwhelmed its potential applications to other disciplines. While the potential of KM in business and public organisations has been explored in many studies, its application in learning organisations has yet to benefit from emerging opportunities arising from the wider spread of learning technologies.

There have been a number of management practices and tools proposed by researchers and practitioners to enhance processes and drive better KM adoption in HE institutions. These are depicted in the KM Lifecycle in Fig. 3. 


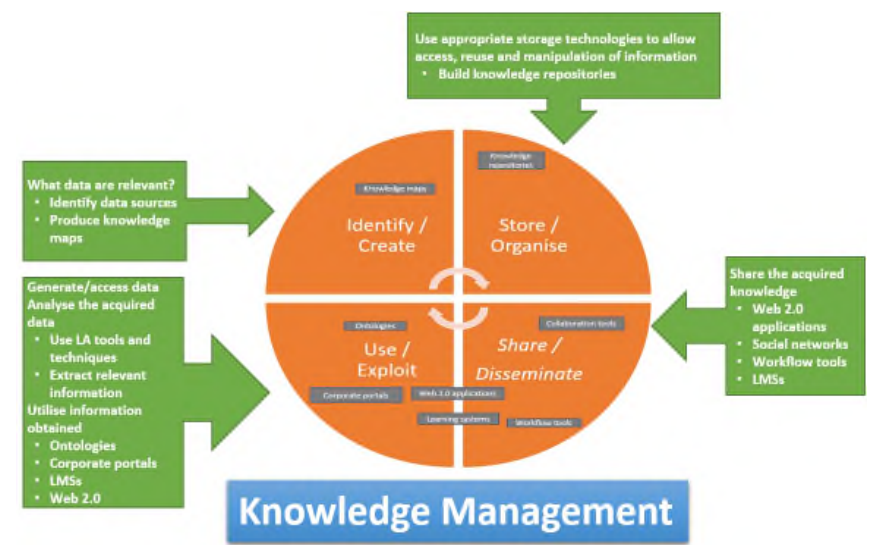

Fig. 3. KM Lifecycle in Learning

The above diagram represents the KM lifecycle and how $\mathrm{KM}$ is used in learning. The orange core reflects the general KM processes: identifying, storing, exploiting and sharing knowledge. The grey boxes depict some the tools utilised in learning to carry out the various $\mathrm{KM}$ processes, such as devising knowledge maps to identify/create knowledge or developing ontologies to exploit knowledge. The green boxes show how these tools may be used by the processes.

\section{Learning Services in Higher Education}

The term "learning services" can mean different things. In a traditional sense, learning services are the different support and enabling services that should be provided to the key stakeholders (i.e. academic staff, admins and students) who are involved in an education programme. These services offered by an HE institution aim to facilitate the learning process, and include management and provision of teaching content, classrooms, libraries, research facilities and so on. With the introduction of online learning, learning services have emerged to reflect learning provided as an online service. Such services are usually referred to as e-learning. In this sense, an e-learning service provided by an HE institution is an online service that enables a learner to access learning materials and/or interact with the teachers and other peer students.

E-learning services include course management, content management, scheduling, personalisation, resource harvesting, games, simulation, podcasting, and so on [11].

Improvements in learning services, such as class management, facility provision and teaching material, will yield development of various aspects of the learning environment, such as student retention, student performance and institution competitive advantage due the interconnection between learning services and the learning environment. Learning Services relate to various aspects of the learning environment

The classification of the dimensions of the Learning services sets the ground for defining the key services that VLEs need to be effective [12]. Emphasising the importance of interaction, resources and materials in teaching materials and resources management services are the core of the VLEs. They host and facilitate the dissemination of the content developed by professors and lectures to students. This service comprises three main areas: Design, Content and Support Management. The first one relates to the mechanisms that enable a common terminology management, and promote the students' appropriation of the learning material based on the philosophical model of the organisation/course (ex. Constructivist or Positivist). Past investigations have demonstrated the importance of design in promoting and/or accelerating the learning process $[13,14,15]$. The second area, Content Management Services, has been demonstrated to be the main influencer in the effectiveness of e-learning by several studies and hence, they are at the centre of learning VLEs and platforms. Finally, the support services are the pillars that the sustain the Content, such as e-library and catalogue, and IT support [16].

Assessments Services are a recurrent theme of analysis in previous investigations [17, 18]. Research showed the importance of having quizzes and assignments periodically in order to ensure that students grasp fundamental concepts in the asynchronous learning process. Similarly, these studies highlighted the importance of having mechanisms for feedingback students reports and evaluation.

Human learning is strongly rooted to interaction and communication with other beings to conceptualise, discuss and apprehend knowledge from different perspectives. Therefore, VLEs need to have communication and interaction services that mimic the natural and physical processes present in classrooms or informal learning environments, which are a major theme in the e-learning and analytics studies [19, 20]. It encompasses wikis, email, chat, dashboards, whiteboards, announcements resources among others.

Finally, the investigation of [21] and [18] provides evidence of the necessity of having services for supporting the course documentation in areas such as course attributes, description and manuals. Although no direct impact on the efficiency of e-learning has been proven, course documentation related services keep organised the education database and facilitate the administration of the information systems surrounding the VLEs.

\section{Learning Analytics Status in Higher Education}

Leading HE institutions worldwide are increasingly applying LA in both academic and administrative processes. Among these institutions, the following examples are provided [22]:

- Purdue uses predictive course analytics system, known as Signals, which is provided by SunGard. The system produces 3-colour indicators (Red, Yellow and Green) to evaluation student behaviours as opposed to past behaviour of successful students

- Rio Salado College has developed a model to assess the likelihood of a student's successful completion of a particular course based on indicators such as LMS activity data, past enrolment, and current enrolment status. They also have developed a student status model, which generates weekly warnings based on student 
login frequency, site engagement, and speed of completing a course.

Other variations of analytics are used in many other institutions. Nevertheless, these tools and solutions are in need of enhancement in terms of efficiency and effectiveness, and are required to be more feasible, more open, and more capable [22]. In the UK, LA is still in its earliest stages, and most institutions have not yet deployed a full LA system but use a variety of platforms, methods and metrics. For example, the UK is known for its world-class higher education system. However, adapting to the increasing involvement of LA can contribute to supporting and retaining the UK's competitive advantage in HE. Some motivations behind introducing LA include: enhancing learning and teaching, increasing retention, and providing students with better feedback [23].

Learning analytics is believed to be capable of addressing a range of challenges and issues in higher education. Studies have shown that learning analytics (LA) has the potential of being powerful for improving learning services in HE [23]. Nevertheless, there are certain criteria for LA to follow in order to get maximum benefit. These include among others: involvement of key actors in the design of the LA methods, assessment through the improvement of learning and teaching processes, and presence in an institution's strategic plan (Shacklock, 2016). The vast potential of learning analytics to alleviate many of these challenges continues however to be untapped [24]. In the UK a limited number of institutions are actually utilising learning analytics.

LA in HE has been subjected to scrutiny and analysis from scholars for some time, with a mixed view about the significance of LA applications in HE. This could be due to the lack of detailed information pertaining to the implementation aspects undertaken by higher education institutions. It is argued in [25] that although the importance of continuous improvement to realise LA in HE to satisfactory levels is recognised in the literature, there is very little data and research available about the process. The current LA products in HE, which use different technologies and business models, are essentially commercial and generally do not apply directly to education models [25].

Some of the issues preventing LA from reaching its full potential are identified in [23]. These issues are summarised as follows:

- Ethical issues in terms of the use of student data by institutions, especially in relation to student consent and privacy

- Students' attempts to 'game the system'. That is, some students endeavour to manipulate analytics in order to attain false positive results thereby compromising the general performance of the system

- Most institutions lack an effective data management system in place. Data is usually inconsistently stored in data silos. This is highly relevant since robust data management is crucial to introducing analytics

- The management lacks a strategic vision. The management is required to drive forward a culture shift in their institutions, which considers data as integral to every aspect of the institution.

A framework for LA in HE is proposed in [5]. The framework is motivated by the potential and opportunities that LA offers in its relevance for educational development and opportunities to personalise learning. According to the authors, the observation and comparison of information flows and social interactions can provide learners with new insights and improve organisational efficiency and effectiveness. The new information can improve individual learning processes and organisational knowledge management processes. It is recognised however that there is ambiguity about the extent of the impact LA will have on education and learning in general. The authors maintain that there are opportunities offered by LA to provide new support for learning activities and stimuli for reflection. The development of LA in HE however should happen with a guiding framework that combines the use of educational data and the protection of learners and their learning.

It is argued in [26] that applying the adaptive education general concepts for resources access, such as tutoring and eLearning systems, is not sufficient for achieving improved learning through knowledge sharing. The approaches must be complemented with knowledge management, informal and social learning and lifelong learning principles. This would generate a large number of knowledge resources in different places and by different people, thereby promoting open innovation and open knowledge principles.

Although LA are important for understanding and improving learning services, its applications are yet to be fully exploited. Reasons behind that vary but are mainly related to the lack of comprehensive LA frameworks that benefit from KM practices.

\section{DISCUSSION}

\section{A. Learning Analytics Frameworks}

There are a number of frameworks in the literature that aim to address learning analytics in a systematic and holistic manner within the overall organisational strategy of the organisation. Some of these frameworks are reviewed in [22], and it is shown that that a more comprehensive approach should be followed to achieve optimal LA results. For instance, the Davenport/Harris framework (2007) focuses on how an organisation should use analytics to optimise competitiveness. Davenport/Harris framework classifies the LA process in two main phases: The Query and Reporting stage, which is a prestage of the analytics, and the Analytics phase. In each phase there are a number of activities to be completed. Each activity has a main focus presented as a question, with actions required to be taken in order to complete the activity. Another framework discussed is the Norris/Baer framework [22]. The framework describes seven elements that are exercised in achieving learning analytics in a higher education institution.

The frameworks only introduce the necessary steps for learning analytics in higher education, but provide no evidence that LA will be effective or successful. 


\section{B. Learning Analytics and Knowledge Management}

LA has been applied to some extent by HE institutions, although the full potential of LA is yet to be achieved mainly due to the lack of an incorporating culture and strategic vision, among other challenges. It has also been shown that KM can be decisive for improving HE institutions' services provided, such improved research, teaching and learning processes, among many other things. It has also been argued that KM in HE institutions comprises complex processes given the large number of elements to be considered, as well as the heterogeneous and contextual nature of higher education. Given the above, LA without knowledge management will not be optimal. The argument stands on the fact that knowledge management is essential to support improvements and innovation in analytics tools [27], which are essential for robust LA. Moreover, LA is required to be embedded in the organisation's strategic vision, and knowledge management can help an organisation translate its strategic vision into action [28]. It is also shown in [29] that knowledge management is an important aspect of any learning process, not only for the sake of managing large amounts of information, but also to allow sharing of that information among different actors.

\section{CONCLUSION AND FURTHER WORK}

The findings indicate that $\mathrm{KM}$ is still a new aspect of management in higher education. LA on the other hand, is still in its early stages worldwide. In the UK for example, most institutions have not yet deployed a full LA system but use a variety of platforms, methods and metrics. The review has maintained that LA, when undertaken by HE institutions, is not considered within a holistic knowledge management strategy, which could provide significant improvement to the outcomes of LA. The importance of integrating $\mathrm{KM}$ and LA in a framework has been presented in this paper to the extent that LA needs $\mathrm{KM}$ in order to be effective, which is evident from the literature. The current use of LA in HE institutions to improve learning is limited. Particularly, a synthesis of knowledge extraction via LA and appropriate handling of such knowledge via knowledge management is not typically implemented in higher education practices, but it constitutes a promising path to improving it.

Although there exist LA frameworks providing the basic procedure for undertaking learning analytics in higher education, they offer no guarantee that LA will be effective or successful. This is mainly because knowledge, which is the natural outcome of learning analytics, is not sufficiently addressed in terms of how it will be utilised and consequently managed. Considering the management of knowledge when conducting LA will help guide the various LA processes at every stage.

For future work, empirical research is suggested. The discussion of the. Evidence from the literature has been presented in the paper supporting the claim of the importance of integrating KM and LA in a framework to the extent that LA needs KM in order to be effective. Empirical research will help substantiate the collected evidence with primary data and provide a better understanding of how KM and LA integration could be implemented.

\section{REFERENCES}

[1] Siemens, G., and Long, P. (2011). Penetrating the fog: Analytics in learning and education. EDUCAUSE review, 46(5), 30.

[2] Sclater, N., Peasgood, A., and Mullan, J. (2016). Learning Analytics in Higher Education.

[3] Vishwakarma, H. R., Tripathy, B. K., and Kothari, D. P. (2014, March). A framework for enhancing quality of learning and knowledge management programmes using analytics. In IT in Business, Industry and Government (CSIBIG), 2014 Conference on (pp. 1-2). IEEE.

[4] Williamson, B. (2016). Digital education governance: data visualization, predictive analytics, and 'real-time'policy instruments. Journal of Education Policy, 31(2), 123-141.

[5] Greller, W., and Drachsler, H. (2012). Translating Learning into Numbers: A Generic Framework for Learning Analytics. Educational technology and society, 15(3), 42-57.

[6] Clow, D. (2012, April). The learning analytics cycle: closing the loop effectively. In Proceedings of the 2nd international conference on learning analytics and knowledge (pp. 134-138). ACM.

[7] Ferguson, R. (2012). Learning analytics: drivers, developments and challenges. International Journal of Technology Enhanced Learning, 4(5-6), 304-317.

[8] Ruipérez-Valiente, J. A., Muñoz-Merino, P. J., Leony, D., and Kloos, C. D. (2015). ALAS-KA: A learning analytics extension for better understanding the learning process in the Khan Academy platform. Computers in Human Behavior, 47, 139-148

[9] Khalil, M., Taraghi, B., and Ebner, M. (2016). Engaging Learning Analytics in MOOCs: the good, the bad, and the ugly. arXiv preprint arXiv: 1606.03776.

[10] Cranfield, D. J., and Taylor, J. (2008). Knowledge management and higher education: a UK case study. The Electronic Journal of Knowledge Management, 6(2), 85-100.

[11] Dagger, D., O'Connor, A., Lawless, S., Walsh, E., and Wade, V. P. (2007). Service-oriented e-learning platforms: From monolithic systems to flexible services. IEEE Internet Computing, 11(3).

[12] Piccoli, G., Ahmad, R. and Ives, B. (2001) 'Web-Based Virtual Learning Environments: A Research Framework and a Preliminary', MIS Quarterly, 25(4), pp. 401-426.

[13] Hong, W., Thong, J. Y. L., Wong, W. M. and Tam, K. Y. (2001) 'Determinants of user acceptance of digital libraries: An empirical examination of individual differences and system characteristics', Journal of Management Information Systems, 18(3), pp. 97-124. doi: 10.1080/07421222.2002.11045692.

[14] Wixom, B. and Todd, P. (2005) 'A theoretical integration of user satisfaction and technology acceptance', Information Systems Research, 16(1), pp. 85-102. doi: 10.1287/isre.1050.0042.

[15] Martínez-Torres, M. R., Toral Marín, S. L., García, F. B., Vázquez, S. G., Oliva, M. A. and Torres, T. (2008) 'A technological acceptance of elearning tools used in practical and laboratory teaching, according to the European higher education area', Behaviour and Information Technology, 27(6), pp. 495-505. doi: 10.1080/01449290600958965.

[16] Fayyoumi, A. and Elia, G. (2015) 'A systemic model for measuring the effectiveness of virtual learning programs', International Journal of Information Technology and Management, 14(4), pp. 305-332. doi: 10.1504/IJITM.2015.072047.

[17] Sun, P. C., Tsai, R. J., Finger, G., Chen, Y. Y. and Yeh, D. (2008) 'What drives a successful e-Learning? An empirical investigation of the critical factors influencing learner satisfaction', Computers and Education, 50(4), pp. 1183-1202. doi: 10.1016/j.compedu.2006.11.007.

[18] Islam, A. K. M. N. (2013) 'Investigating e-learning system usage outcomes in the university context', Computers and Education. Elsevier Ltd, 69, pp. 387-399. doi: 10.1016/j.compedu.2013.07.037.

[19] Rodríguez Ribón, J. C., García Villalba, L. J., de Miguel Moro, T. P. and Kim, T. hoon (2015) 'Solving technological isolation to build virtual learning communities', Multimedia Tools and Applications, 74(19), pp. 8521-8539. doi: 10.1007/s11042-013-1542-5. 
[20] Pattanasith, S., Rampai, N. and Kanperm, J. (2015) 'The Development Model of Learning though Virtual Learning Environments (VLEs) for Graduated Students, Department of Educational Technology, Faculty of Education, Kasetsart University', Procedia - Social and Behavioral Sciences. Elsevier B.V., 176, pp. 60-64. doi: 10.1016/j.sbspro.2015.01.444.

[21] Lee, Y. (2006) 'An empirical investigation into factors influencing the adoption of an e-learning system', Online Information Review. Emerald Group Publishing Limited, 30(5), pp. 517-541. doi: 10.1108/14684520610706406.

[22] Norris, D. M., and Baer, L. L. (2013). Building organizational capacity for analytics. Boulder, CO: Educause. Retrieved May, 10, 2015.

[23] Shacklock, X. (2016). From Bricks to Clicks: The Potential of Data and Analytics in Higher Education. Higher Education Commission.

[24] Bakharia, A., Corrin, L., de Barba, P., Kennedy, G., Gašević, D., Mulder, R., ... and Lockyer, L. (2016, April). A conceptual framework linking learning design with learning analytics. In Proceedings of the Sixth International Conference on Learning Analytics and Knowledge (pp. 329-338). ACM.
[25] Mattingly, K. D., Rice, M. C., and Berge, Z. L. (2012). Learning analytics as a tool for closing the assessment loop in higher education. Knowledge Management and E-Learning: An International Journal (KMandEL), 4(3), 236-247.

[26] Blanco, Á. F., García-Peñalvo, F. J., and Sein-Echaluce, M. (2013, November). A methodology proposal for developing adaptive cMOOC. In Proceedings of the First International Conference on Technological Ecosystem for Enhancing Multiculturality (pp. 553-558). ACM.

[27] Layman, L., Seaman, C., Falessi, D., and Diep, M. (2015, May). Ask the engineers: exploring repertory grids and personal constructs for software data analysis. In Proceedings of the Eighth International Workshop on Cooperative and Human Aspects of Software Engineering (pp. 81-84). IEEE Press.

[28] Piccoli, G., Ahmad, R. and Ives, B. (2001) 'Web-Based Virtual Learning Environments: A Research Framework and a Preliminary', MIS Quarterly, 25(4), pp. 401-426.

[29] Fidalgo-Blanco, Á., Sein-Echaluce, M. L., and García-Peñalvo, F. J. (2015). Methodological Approach and Technological Framework to break the current limitations of MOOC model. Journal of Universal Computer Science, 21(5), 712-734. 
2018-12-31

\title{
Knowledge management to support learning analytics in Higher Education
}

\author{
Alenezi, Abdullah
}

IEEE

Alenezi A, Emmanouilidis C, Al-Ashaab A, Knowledge management to support learning analytics in Higher Education. 2018 IEEE 5th International Congress on Information Science and Technology (CiSt), 21-27 October 2018, Marrakech, Morocco.

https://doi.org/10.1109/CIST.2018.8596653

Downloaded from Cranfield Library Services E-Repository 